\title{
Article \\ Factors Influencing Australian Healthcare Workers' COVID-19 Vaccine Intentions across Settings: A Cross-Sectional Survey
}

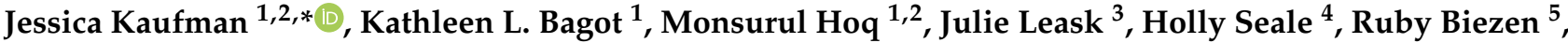 \\ Lena Sanci $^{5}$, Jo-Anne Manski-Nankervis ${ }^{5}$ (D), J. Simon Bell ${ }^{6}$, Jane Munro 1,2,7, Carol Jos ${ }^{1}$, \\ Darren Suryawijaya Ong ${ }^{1}$, Jane Oliver ${ }^{1,8}$, Jane Tuckerman ${ }^{1,2}$ and Margie Danchin 1,2,7
}

1 Vaccine Uptake Group, Murdoch Children's Research Institute, Melbourne 3052, Australia; katie.bagot@mcri.edu.au (K.L.B.); monsurul.hoq@mcri.edu.au (M.H.); Jane.Munro@rch.org.au (J.M.); carol.jos@mcri.edu.au (C.J.); darren.suryawijaya@mcri.edu.au (D.S.O.); jane.oliver@mcri.edu.au (J.O.); jane.tuckerman@mcri.edu.au (J.T.); margie.danchin@rch.org.au (M.D.)

2 Department of Paediatrics, University of Melbourne, Melbourne 3052, Australia

3 Susan Wakil School of Nursing and Midwifery, University of Sydney, Sydney 2052, Australia; julie.leask@sydney.edu.au

4 School of Population Health, University of New South Wales, Sydney 2052, Australia; h.seale@unsw.edu.au

5 Department of General Practice, University of Melbourne, Carlton 3010, Australia; ruby.biezen@unimelb.edu.au (R.B.); 1.sanci@unimelb.edu.au (L.S.); jomn@unimelb.edu.au (J.-A.M.-N.)

6 Centre for Medicine Use and Safety, Faculty of Pharmacy and Pharmaceutical Sciences, Monash University, Melbourne 3052, Australia; simon.bell2@monash.edu

7 The Royal Children's Hospital, Melbourne 3052, Australia

8 The Peter Doherty Institute for Infection and Immunity, University of Melbourne, Melbourne 3000, Australia

* Correspondence: jess.kaufman@mcri.edu.au

check for

updates

Citation: Kaufman, J.; Bagot, K.L.;

Hoq, M.; Leask, J.; Seale, H.; Biezen,

R.; Sanci, L.; Manski-Nankervis, J.-A.; Bell, J.S.; Munro, J.; et al. Factors Influencing Australian Healthcare Workers' COVID-19 Vaccine Intentions across Settings: A Cross-Sectional Survey. Vaccines 2022, 10,3. https://doi.org/10.3390/ vaccines 10010003

Academic Editor: Vincenzo Baldo

Received: 27 November 2021

Accepted: 17 December 2021

Published: 21 December 2021

Publisher's Note: MDPI stays neutral with regard to jurisdictional claims in published maps and institutional affiliations.

Copyright: (C) 2021 by the authors. Licensee MDPI, Basel, Switzerland. This article is an open access article distributed under the terms and conditions of the Creative Commons Attribution (CC BY) license (https:// creativecommons.org/licenses/by/ $4.0 /)$.

\begin{abstract}
Healthcare workers' COVID-19 vaccination coverage is important for staff and patient safety, workforce capacity and patient uptake. We aimed to identify COVID-19 vaccine intentions, factors associated with uptake and information needs for healthcare workers in Victoria, Australia. We administered a cross-sectional online survey to healthcare workers in hospitals, primary care and aged or disability care settings (12 February-26 March 2021). The World Health Organization Behavioural and Social Drivers of COVID-19 vaccination framework informed survey design and framing of results. Binary regression results adjusted for demographics provide risk differences between those intending and not intending to accept a COVID-19 vaccine. In total, 3074 healthcare workers completed the survey. Primary care healthcare workers reported the highest intention to accept a COVID-19 vaccine (84\%, 755/898), followed by hospital-based $(77 \%, 1396 / 1811)$ and aged care workers $(67 \%, 243 / 365)$. A higher proportion of aged care workers were concerned about passing COVID-19 to their patients compared to those working in primary care or hospitals. Only $25 \%$ felt they had sufficient information across five vaccine topics, but those with sufficient information had higher vaccine intentions. Approximately half thought vaccines should be mandated. Despite current high vaccine rates, our results remain relevant for booster programs and future vaccination rollouts.
\end{abstract}

Keywords: immunization; vaccination; coronavirus; vaccine acceptance; communication

\section{Introduction}

Healthcare workers (HCWs) were prioritised to receive COVID-19 vaccines in most countries, due to the high occupational risk of COVID-19 infection [1-4]. Systematic reviews of the international literature report that HCW vaccine acceptance rates between countries varied between $28 \%$ and $96 \%$ (data published up to March 2021) [5,6] with hesitancy associated with vaccine safety (e.g., side effects), rapid development, and vaccine efficacy and effectiveness (data published up to February 2021) [7]. COVID-19 vaccine intentions [8,9] and vaccine uptake $[10,11]$ also varies by clinical discipline and setting internationally. As of 26 November 2021, there have been 4092 COVID-19 cases among clinical HCWs in Victoria, Australia, with $66 \%$ of infections likely acquired in workplace [12]. 
Of these workplace cases, 50\% have been in aged care or disability care workers and 39\% in nurses, with most occurring prior to the availability of COVID-19 vaccines [12].

By 10 November 2021, 81.5\% of Australians aged over 16 years have received two doses of a COVID-19 vaccine. Rates of vaccine uptake among Australian HCWs are only reported separately for aged care workers, of whom $95.8 \%(n=252,249)$ were fully vaccinated (10 November 2021) [13]. National mandatory vaccination policies apply to aged care workers [14] and state policies apply for other HCWs, which vary across jurisdictions and settings $[15,16]$. However, there are no publicly available data on coverage for other Australian HCWs by role or workplace setting.

Our study was conducted at the beginning of the vaccine rollout in Australia in early 2021, prior to the introduction of any vaccination requirements for HCWs. We surveyed those working in hospitals, primary care and aged and disability care settings who were prioritised to receive the COVID-19 vaccine in Victoria, Australia, to understand COVID19 vaccine intentions and the factors that influence uptake. We aimed to (1) identify vaccination intention rates by setting for frontline healthcare, and aged and disability care workers, (2) explore factors associated with vaccine hesitancy or refusal and (3) identify information needs to support receiving and recommending the COVID-19 vaccine.

\section{Materials and Methods}

\subsection{Participants, Setting and Context}

As part of a larger, mixed-methods study [17], this cross-sectional study was conducted in Victoria, Australia between 12 February and 26 March 2021 at an early stage of the Australian vaccination program rollout. Although Victoria was the epicentre for Australian COVID-19 cases during 2020 and had a 5-day "circuit breaker" lockdown between 12-17 February 2021 [18], Victoria had minimal community transmission [19] and few COVID-19 related restrictions at the time of this survey. The study was funded by the Victorian Department of Health and was conducted to support the Victorian Government's COVID19 vaccine communication planning.

Australia's vaccination program commenced 22 February 2021, with Pfizer-BioNTech (BNT162b2) and AstraZeneca (Oxford, ChAdOx1) COVID-19 vaccines available to those prioritised in Phase 1a (i.e., quarantine and border workers, frontline HCW sub-groups and other HCWs, aged care and disability care staff and residents) and $1 \mathrm{~b}$ (i.e., general public aged 70 years and over, non-frontline HCWs, Aboriginal and Torres Strait Islander people aged over 55 years, adults with an underlying condition or disability, other critical and high risk workers) [3]. Both of these vaccines were available to these prioritised groups via hospital-based and general practice (from 22 March 2021)-based vaccination programs. In January 2021, media commentary was focusing on the lower effectiveness of AstraZeneca (compared to Pfizer) $[20,21]$ and by mid-March 2021, several European countries had suspended the use of AstraZeneca due to risks of clotting [22].

HCWs living in Victoria were eligible to complete the online survey. Eligible occupations included nurses, medical doctors, pharmacists, allied health professionals, personal support workers, ambulance staff or paramedics, and other health professionals (e.g., dentist, psychologist, etc.), working at a hospital, healthcare practice (community or private) or residential aged or disability care setting in Victoria. A combination of snowballing recruitment and research advertisements across health services, clinical colleges, councils, associations, unions, networks, and Facebook were used to recruit participants.

\subsection{Data Collection}

The survey was developed specifically for COVID-19 vaccination with between 35 and 46 items, depending on participant responses (see Table S1 for full survey). We drew 11 items from the World Health Organization Behavioural and Social Drivers of Immunisation (BeSD) COVID-19 vaccine survey that covers the domains of thinking and feeling, social processes and practical issues, as well as the motivation domain that measures vaccine intentions [23]. A further 13 items were developed by the research team, in consultation 
with the Victorian Government Department of Health representatives. In addition to demographics (7 items) and workforce characteristics (4 items), survey items covered vaccine intentions (i.e., 'If a COVID-19 vaccine were recommended for you, would you get it?' with response options 'Yes', 'No', 'Not sure'), factors participants identify as influencing their vaccination decision making, vaccine concerns and beliefs, perceived convenience of getting the vaccine and information needs. We also included items covering perceptions on mandating and recommending the vaccine to patients. Response options were categorical.

The 10-minute survey and participant information statement were administered online via REDCap [24]. The survey could be completed anonymously, and consent was implied by survey completion. The Royal Children's Hospital Human Research Ethics Committee provided ethics approval for the mixed-methods study (HREC/72845/RCHM-2021).

\subsection{Analysis}

Participants who did not report their vaccine intention or occupational setting were excluded, as were those with unclear or uncategorisable (e.g., multiple settings) occupations settings provided. As multiple professional roles (e.g., physicians, nurses) are in each setting, results are presented for the total sample, and then by hospital, primary care and aged/disability setting. Categorical responses are presented as number and percentages. For questions supporting multiple responses, results are presented in order of frequency of selection. Binary regressions were used to estimate risk differences (RD) with 95\% confidence intervals (CIs) between those intending and those unsure/not intending to accept a COVID-19 vaccine for different demographic characteristics. For comparing the intention to accept a COVID-19 vaccine based on different factors, binary regressions were used adjusted for age, sex, cultural and linguistically diverse (CALD) status (born overseas and/or speaking a language other than English at home), employment status and regionality. With missing data rates $<5 \%$ across surveys, we have analysed complete cases. Results are presented according to the BeSD framework [25] which outlines the measurable and modifiable drivers of vaccine uptake (Figure 1). Where responses to one question are relevant to more than one component of the BeSD framework, results are presented in only one section (e.g., all information results are presented in practical issues). Data were analysed using Stata 16.1 [26].

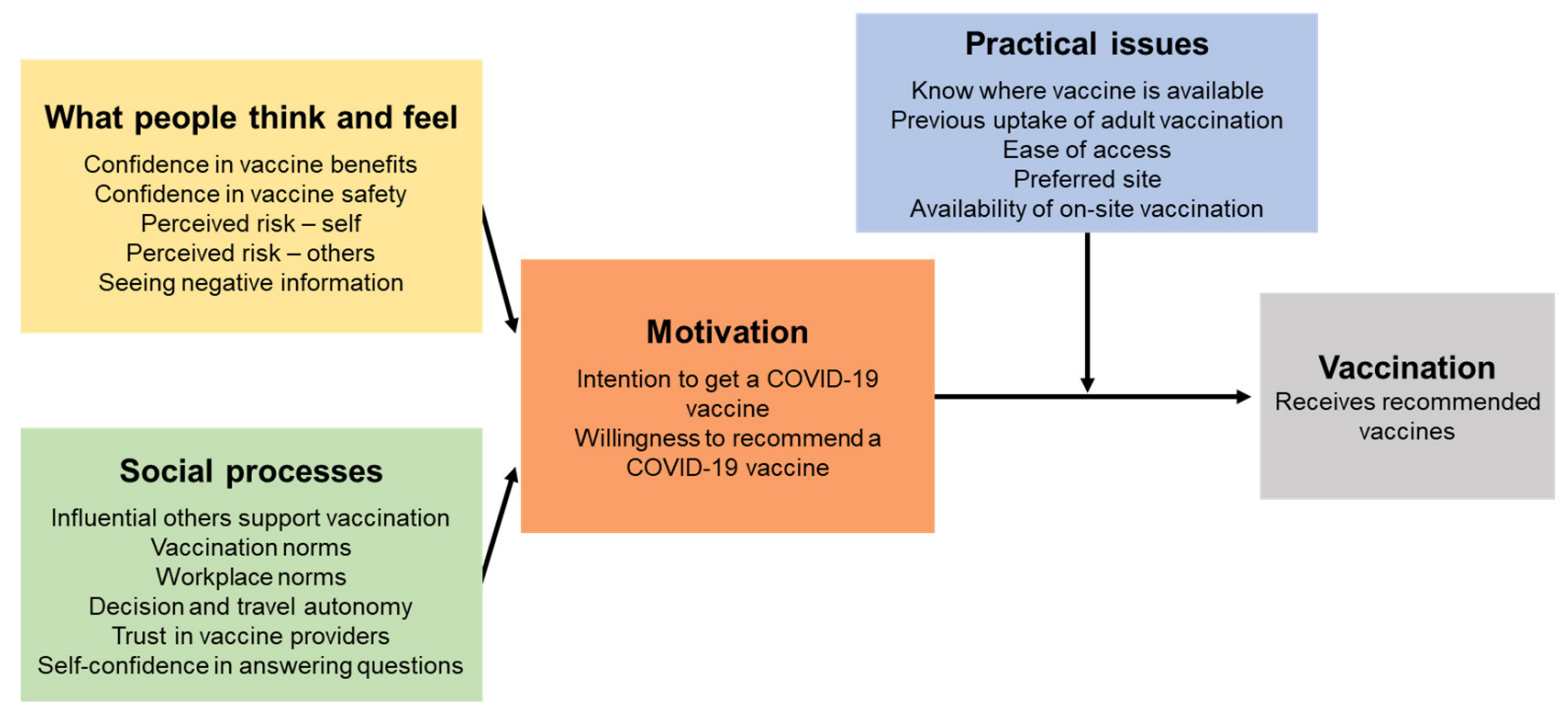

Figure 1. The Behavioural and Social Drivers of COVID-19 vaccination framework [25]. CC BY-NCSA 3.0 IGO, https: / / www.who.int/publications/i/item/WHO-2019-nCoV-vaccination-demandplanning-2021.1 (accessed on 15 December 2021). 


\section{Results}

In the first quarter of 2021, a total of 3224 participants completed the survey, of which 150 respondents were excluded as they did not report their vaccine intentions $(n=7)$, did not report their occupational setting $(n=28)$ or reported it as 'other' $(n=115)$. Demographic characteristics of the remaining 3074 participants differed across settings in some key areas (Table 1). Compared to those working in hospital or aged care settings, fewer HCWs in primary care settings were female, fewer were nurses and more were employed full time. The proportion of CALD participants and those living in regional areas was higher in aged care than in other settings. A higher proportion of HCWs in hospital settings were younger than 50 years.

Table 1. Demographic characteristics of participants, by setting.

\begin{tabular}{|c|c|c|c|c|}
\hline $\begin{array}{l}\text { Demographic } \\
\text { Characteristics }\end{array}$ & $\begin{array}{l}\text { Hospital } \\
\%(n / \mathrm{N})\end{array}$ & $\begin{array}{c}\text { Primary Care } \\
\%(n / \mathrm{N})\end{array}$ & $\begin{array}{l}\text { Aged Care } \\
\%(n / \mathrm{N})\end{array}$ & Total \\
\hline & $\mathrm{N}=1811$ & $\mathrm{~N}=898$ & $\mathrm{~N}=365$ & $\mathrm{~N}=3074$ \\
\hline \multicolumn{5}{|l|}{ Gender \# } \\
\hline Female & $88.6(1552 / 1751)$ & $77.1(671 / 870)$ & $89.8(309 / 344)$ & $85.4(2532 / 2965)$ \\
\hline \multicolumn{5}{|l|}{ Age $\#$} \\
\hline $18-49$ & $59.5(1044 / 1754)$ & $50.2(436 / 869)$ & $47.8(163 / 341)$ & $55.4(1643 / 2964)$ \\
\hline $50 \leq$ & $40.5(710 / 1754)$ & $49.8(433 / 869)$ & $52.2(178 / 341)$ & $44.6(1321 / 2964)$ \\
\hline \multicolumn{5}{|l|}{ Country of birth } \\
\hline Born in Australia & $70.2(1272 / 1811)$ & $68.5(615 / 898)$ & $57.5(210 / 365)$ & $68.2(2097 / 3074)$ \\
\hline \multicolumn{5}{|c|}{ Indigenous Australian (Aboriginal or Torres Strait Islander) ${ }^{\#}$} \\
\hline Yes & $0.5(8 / 1749)$ & $1.0(9 / 860)$ & $2.3(8 / 341)$ & $0.8(25 / 2950)$ \\
\hline \multicolumn{5}{|c|}{ Language other than English spoken at home ${ }^{\#}$} \\
\hline Yes & $13.7(235 / 1717)$ & $15.9(134 / 843)$ & $27.2(89 / 327)$ & $15.9(458 / 2887)$ \\
\hline \multicolumn{5}{|c|}{ Culturally and linguistically diverse ${ }^{\wedge, \#}$} \\
\hline Yes & $33.3(592 / 1780)$ & $36.9(324 / 878)$ & $47.5(168 / 354)$ & $36.0(1084 / 3012)$ \\
\hline \multicolumn{5}{|l|}{ Occupation } \\
\hline Nurse & $75.2(1362 / 1811)$ & $46.8(420 / 898)$ & $79.2(289 / 365)$ & $67.4(2071 / 3074)$ \\
\hline Medical Doctor & $5.6(102 / 1811)$ & $7.6(68 / 898)$ & $0.3(1 / 365)$ & $5.6(171 / 3074)$ \\
\hline Pharmacist & $1.2(22 / 1811)$ & $3.0(27 / 898)$ & $1.1(4 / 365)$ & $1.7(53 / 3074)$ \\
\hline $\begin{array}{l}\text { Allied Health } \\
\text { Professional }\end{array}$ & $9.5(172 / 1811)$ & $6.3(57 / 898)$ & $0.8(3 / 365)$ & $7.5(232 / 3074)$ \\
\hline $\begin{array}{l}\text { Personal support } \\
\text { staff }\end{array}$ & $0.2(4 / 1811)$ & $1.2(11 / 898)$ & $14.0(51 / 365)$ & $2.1(66 / 3074)$ \\
\hline Ambulance staff & $0.4(8 / 1811)$ & $12.9(116 / 898)$ & $0.0(0 / 365)$ & $4.0(124 / 3074)$ \\
\hline Other & $7.8(141 / 1811)$ & $22.2(199 / 898)$ & $4.7(17 / 365)$ & $11.6(357 / 3074)$ \\
\hline \multicolumn{5}{|l|}{$\begin{array}{c}\text { Employment } \\
\text { status }\end{array}$} \\
\hline Full-time & $39.2(681 / 1737)$ & $48.0(415 / 864)$ & $32.2(109 / 339)$ & $41.0(1205 / 2940)$ \\
\hline \multicolumn{5}{|l|}{ Regionality \# } \\
\hline Regional & $20.4(328 / 1609)$ & $27.6(221 / 802)$ & $42.1(135 / 321)$ & $25.0(684 / 2732)$ \\
\hline Metropolitan & $79.6(1281 / 1609)$ & $72.4(581 / 802)$ & $57.9(186 / 321)$ & $75.0(2048 / 2732)$ \\
\hline
\end{tabular}


Table 1. Cont.

\begin{tabular}{|c|c|c|c|c|}
\hline $\begin{array}{l}\text { Demographic } \\
\text { Characteristics }\end{array}$ & $\begin{array}{l}\text { Hospital } \\
\%(n / \mathrm{N})\end{array}$ & $\begin{array}{c}\text { Primary Care } \\
\%(n / \mathrm{N})\end{array}$ & $\begin{array}{c}\text { Aged Care } \\
\%(n / \mathrm{N})\end{array}$ & Total \\
\hline \multicolumn{5}{|l|}{ Any comorbidity \# } \\
\hline Yes & $32.4(515 / 1589)$ & $33.5(269 / 803)$ & $35.5(110 / 310)$ & $33.1(894 / 2702)$ \\
\hline \multicolumn{5}{|c|}{ Has been tested for COVID ${ }^{\#}$} \\
\hline Yes & $83.0(1494 / 1800)$ & $68.0(609 / 895)$ & $84.9(309 / 364)$ & $78.8(2412 / 3059)$ \\
\hline
\end{tabular}

Note: ${ }^{\#}$ indicates missing data; ^ CALD = born outside Australia and/or speaks a language other than English at home.

\subsection{Motivation}

Primary care HCWs reported the highest intention to accept a COVID-19 vaccine (84\%, $755 / 898)$, followed by hospital-based HCWs $(77 \%, 1396 / 1811)$ and aged care workers $(67 \%$, $243 / 365$ ) (Table 2). Intention to be vaccinated was higher among men, people aged 50 years or older, employed full time or living in major cities. Compared to nurses (77\%, 1674/2169), the intention to be vaccinated was $17 \%$ (95\% CI 13 to $21 \%$ ) higher in medical doctors and $21 \%$ (95\% CI 9 to 33\%) lower in personal support staff.

Table 2. Demographic characteristics associated with COVID-19 vaccine acceptance, by total sample.

\begin{tabular}{|c|c|c|c|c|c|c|c|}
\hline \multirow[t]{2}{*}{ Characteristic } & \multirow[t]{2}{*}{ All HCWs, N } & \multicolumn{3}{|c|}{ Would Get the COVID-19 Vaccine? \% (n) } & \multirow[t]{2}{*}{$\begin{array}{c}\text { Unadjusted } \\
\text { Risk Difference } \\
\text { (Difference in } \\
\text { Proportion) }{ }^{\wedge} * *\end{array}$} & \multirow[t]{2}{*}{$95 \% \mathrm{CI}$} & \multirow[t]{2}{*}{$p$-Value } \\
\hline & & Yes & Not Sure & No & & & \\
\hline Total & 3074 & $77.9(2394)$ & $14.0(429)$ & $8.1(251)$ & $\mathrm{N} / \mathrm{A}$ & & \\
\hline \multicolumn{8}{|l|}{ Gender \# } \\
\hline Female & 2532 & $78.3(1982)$ & $14.4(365)$ & $7.3(185)$ & & & \\
\hline Male & 392 & $85.5(335)$ & $7.7(30)$ & $6.9(27)$ & 7.2 & 3.3 to 11.0 & $<0.001$ \\
\hline $\begin{array}{l}\text { Prefer not to } \\
\text { say }\end{array}$ & 41 & $31.7(13)$ & $24.4(10)$ & $43.9(18)$ & -46.6 & $\begin{array}{c}-60.9 \text { to } \\
-32.2\end{array}$ & $<0.001$ \\
\hline \multicolumn{8}{|l|}{ Age $\#$} \\
\hline $18-49$ & 1643 & $74.1(1217)$ & $16.3(268)$ & $9.6(158)$ & & & \\
\hline $50=<$ & 1321 & $84.4(1115)$ & $10.4(138)$ & $5.1(68)$ & 10.3 & 7.5 to 13.2 & $<0.001$ \\
\hline \multicolumn{8}{|l|}{$\begin{array}{l}\text { Country of } \\
\text { birth }\end{array}$} \\
\hline $\begin{array}{c}\text { Born in } \\
\text { Australia }\end{array}$ & 2097 & $78.4(1645)$ & 13.3 (279) & $8.2(173)$ & & & \\
\hline $\begin{array}{l}\text { Not born in } \\
\text { Australia }\end{array}$ & 977 & 76.7 (749) & $15.4(150)$ & $8.0(78)$ & -1.8 & -5.0 to 1.4 & 0.272 \\
\hline \multicolumn{8}{|l|}{$\begin{array}{l}\text { Aboriginal or } \\
\text { Torres Strait } \\
\text { Islander } \#\end{array}$} \\
\hline Yes & 25 & $60.0(15)$ & $24.0(6)$ & $16.0(4)$ & & & \\
\hline No & 2893 & $79.4(2297)$ & $13.4(387)$ & $7.2(209)$ & 19.4 & 0.1 to 38.7 & 0.048 \\
\hline
\end{tabular}


Table 2. Cont.

\begin{tabular}{|c|c|c|c|c|c|c|c|}
\hline \multirow[t]{2}{*}{ Characteristic } & \multirow[t]{2}{*}{ All HCWs, $\mathbf{N}$} & \multicolumn{3}{|c|}{ Would Get the COVID-19 Vaccine? \% (n) } & \multirow[t]{2}{*}{$\begin{array}{c}\text { Unadjusted } \\
\text { Risk Difference } \\
\text { (Difference in } \\
\text { Proportion) }{ }^{\wedge}, *\end{array}$} & \multirow[t]{2}{*}{$95 \% \mathrm{CI}$} & \multirow[t]{2}{*}{$p$-Value } \\
\hline & & Yes & Not Sure & No & & & \\
\hline $\begin{array}{l}\text { Prefer not to } \\
\text { say }\end{array}$ & 32 & $34.4(11)$ & $28.1(9)$ & $37.5(12)$ & -25.6 & -50.9 to -0.3 & 0.047 \\
\hline \multicolumn{8}{|c|}{ Language other than English spoken at home ${ }^{\#}$} \\
\hline Yes & 458 & $75.5(346)$ & $17.2(79)$ & $7.2(33)$ & & & \\
\hline No & 2429 & $79.1(1921)$ & $13.1(318)$ & $7.8(190)$ & 3.5 & -0.7 to 7.8 & 0.103 \\
\hline \multicolumn{8}{|c|}{ Culturally and linguistically diverse ${ }^{\wedge, \#}$} \\
\hline Yes & 1084 & $76.7(831)$ & $15.1(164)$ & $8.2(89)$ & & & \\
\hline No & 1928 & $78.4(1511)$ & $13.4(258)$ & $8.2(159)$ & 1.7 & -1.4 to 4.8 & 0.282 \\
\hline \multicolumn{8}{|l|}{ Occupation } \\
\hline Nurse & 2071 & 76.9 (1592) & 14.4 (299) & 8.7 (180) & & & \\
\hline $\begin{array}{l}\text { Medical } \\
\text { Doctor }\end{array}$ & 171 & $93.6(160)$ & $4.1(7)$ & $2.3(4)$ & 16.7 & 12.6 to 20.8 & $<0.001$ \\
\hline Pharmacist & 53 & $96.2(51)$ & $1.9(1)$ & $1.9(1)$ & 19.4 & 13.9 to 24.8 & $<0.001$ \\
\hline $\begin{array}{l}\text { Allied Health } \\
\text { Professional }\end{array}$ & 232 & 76.3 (177) & $17.2(40)$ & $6.5(15)$ & -0.6 & -6.3 to 5.2 & 0.844 \\
\hline $\begin{array}{c}\text { Personal } \\
\text { support staff }\end{array}$ & 66 & $56.1(37)$ & $25.8(17)$ & $18.2(12)$ & -20.8 & -32.9 to -8.7 & 0.001 \\
\hline $\begin{array}{l}\text { Ambulance } \\
\text { staff }\end{array}$ & 124 & $79.8(99)$ & $12.9(16)$ & $7.3(9)$ & 3.0 & -4.3 to 10.3 & 0.425 \\
\hline Other & 357 & 77.9 (278) & $13.7(49)$ & $8.4(30)$ & 1.0 & -3.7 to 5.7 & 0.675 \\
\hline \multicolumn{8}{|l|}{$\begin{array}{l}\text { Occupation } \\
\text { settings }\end{array}$} \\
\hline Hospital & 1811 & 77.1 (1396) & $14.4(260)$ & $8.6(155)$ & & & \\
\hline $\begin{array}{l}\text { Primary care } \\
\text { (community } \\
\text { or private } \\
\text { practice) }\end{array}$ & 898 & 84.1 (755) & $10.7(96)$ & $5.2(47)$ & 7.0 & 3.9 to 10.1 & $<0.001$ \\
\hline $\begin{array}{l}\text { Residential } \\
\text { aged or } \\
\text { disability } \\
\text { care facility }\end{array}$ & 365 & $66.6(243)$ & $20.0(73)$ & $13.4(49)$ & -10.5 & -15.7 to -5.3 & $<0.001$ \\
\hline \multicolumn{8}{|l|}{$\begin{array}{c}\text { Employment } \\
\text { status }\end{array}$} \\
\hline Full-time & 1205 & 81.4 (981) & $11.8(142)$ & $6.8(82)$ & & & \\
\hline Part-time & 1735 & 76.9 (1334) & $15.0(261)$ & $8.1(140)$ & -4.5 & -7.5 to -1.6 & 0.003 \\
\hline \multicolumn{8}{|l|}{ Regionality \# } \\
\hline Regional & 684 & $76.3(522)$ & $15.1(103)$ & $8.6(59)$ & & & \\
\hline Metropolitan & 2048 & $82.0(1680)$ & $12.5(256)$ & $5.5(112)$ & 5.7 & 2.1 to 9.3 & 0.002 \\
\hline
\end{tabular}


Table 2. Cont.

\begin{tabular}{|c|c|c|c|c|c|c|c|}
\hline \multirow[t]{2}{*}{ Characteristic } & \multirow[t]{2}{*}{ All HCWs, N } & \multicolumn{3}{|c|}{ Would Get the COVID-19 Vaccine? \% ( $n$ ) } & \multirow[t]{2}{*}{$\begin{array}{c}\text { Unadjusted } \\
\text { Risk Difference } \\
\text { (Difference in } \\
\text { Proportion) }{ }^{\wedge} * *\end{array}$} & \multirow[t]{2}{*}{$95 \%$ CI } & \multirow[t]{2}{*}{$p$-Value } \\
\hline & & Yes & Not Sure & No & & & \\
\hline \multicolumn{8}{|l|}{$\begin{array}{c}\text { Any } \\
\text { comorbidity }\end{array}$} \\
\hline Yes & 894 & $80.4(719)$ & $13.4(120)$ & $6.2(55)$ & & & \\
\hline No & 1808 & $78.5(1420)$ & $13.8(250)$ & $7.6(138)$ & -1.9 & -5.1 to 1.3 & 0.251 \\
\hline \multicolumn{8}{|l|}{$\begin{array}{l}\text { Has been } \\
\text { tested for } \\
\text { COVID }\end{array}$} \\
\hline Yes & 2412 & $79.7(1922)$ & $14.1(339)$ & $6.3(151)$ & & & \\
\hline No & 647 & $71.3(461)$ & $13.4(87)$ & $15.3(99)$ & -8.4 & -12.3 to -4.6 & $<0.001$ \\
\hline
\end{tabular}

Eighty percent of participants $(80 \%, 2388 / 2981)$ would recommend a COVID-19 vaccine to eligible patients. Aged care workers were the least likely to recommend the vaccine $(65 \%, 227 / 348)$ compared to hospital $(80 \%, 1412 / 1759)$ or primary care HCWs $(86 \%$, $749 / 874)$. Of those HCWs who would not make a recommendation, only $25 \%(149 / 593)$ were planning to get the vaccine themselves.

\subsection{Thinking and Feeling}

\subsubsection{Factors Influencing COVID-19 Vaccine Decision-Making}

The factors HCWs most commonly perceived as influencing their personal vaccine decision making were vaccine safety $(73 \%, 2243 / 3074)$, vaccine efficacy $(71 \%, 2170 / 3074)$ and seeing how people overseas reacted to the vaccines $(56 \%, 1708 / 3074)$. However, the factors statistically associated with the intention to accept a vaccine were vaccine availability at the workplace and vaccine recommendation by professional society (Figure 2 and Table S2). The associations were weak between the intention to vaccinate and brand of vaccine offered, manufacturing country, seeing how people overseas reacted to the vaccine or information about the approval process for vaccination in Australia.

\subsubsection{Vaccine Concerns for Those Unsure or Not Intending to Accept the Vaccine}

Of those HCWs who were unsure or not intending to accept a COVID-19 vaccine ( $n=680$ ), the primary concern across all settings was the belief that the vaccines have not been tested enough for safety $(73 \%, 497 / 680)$. While concern about potential long-term effects of the vaccine was the next most common concern in hospital $(68 \%, 284 / 415)$ and aged care settings $(72 \%, 88 / 122)$, primary care HCWs were more concerned about serious reactions $(48 \%, 68 / 143)$ (Figure 3 and Table S3). 


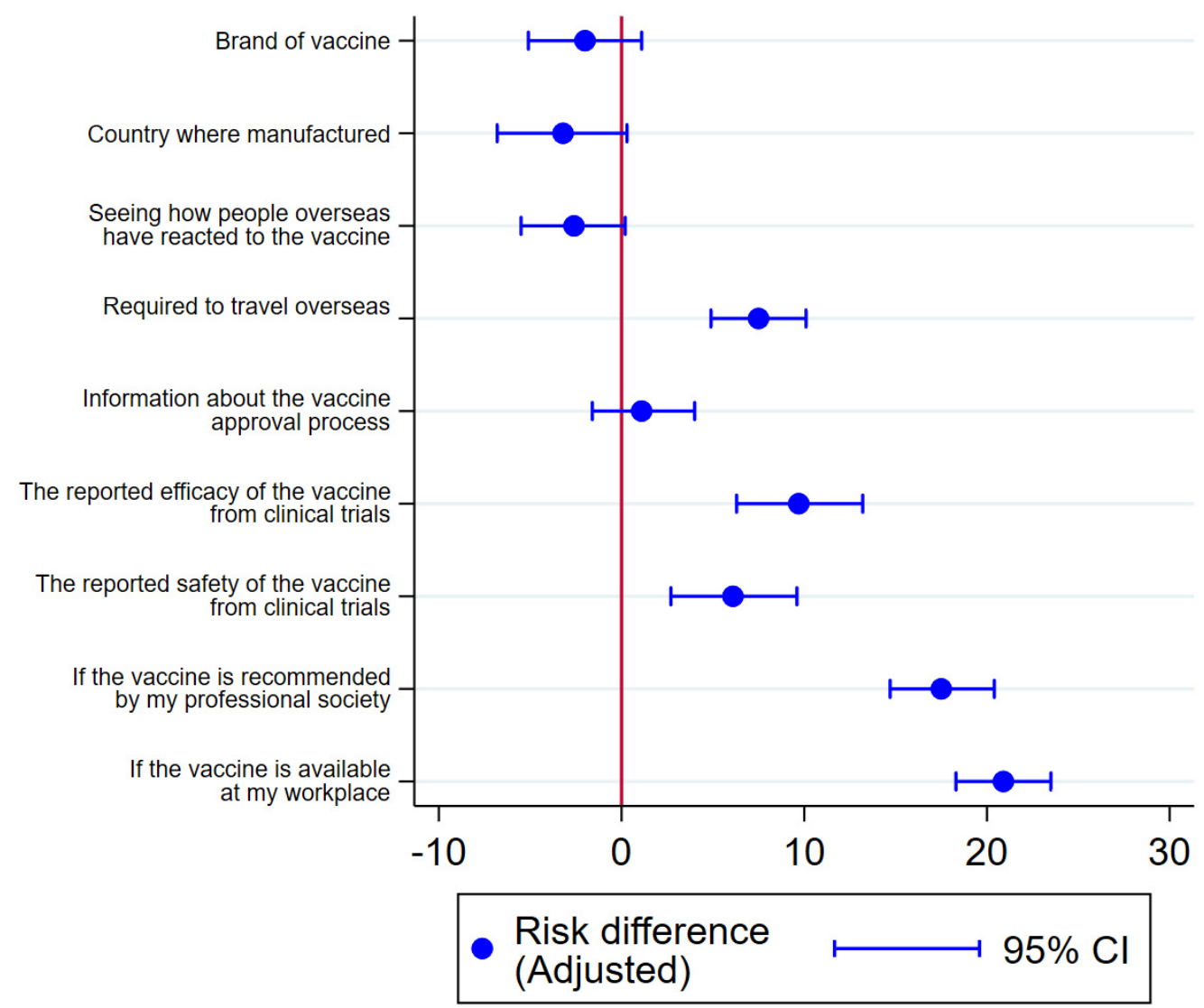

Figure 2. Factors associated with intention to accept a COVID-19 vaccine. Risk difference adjusted for age, sex, CALD, employment and remoteness.

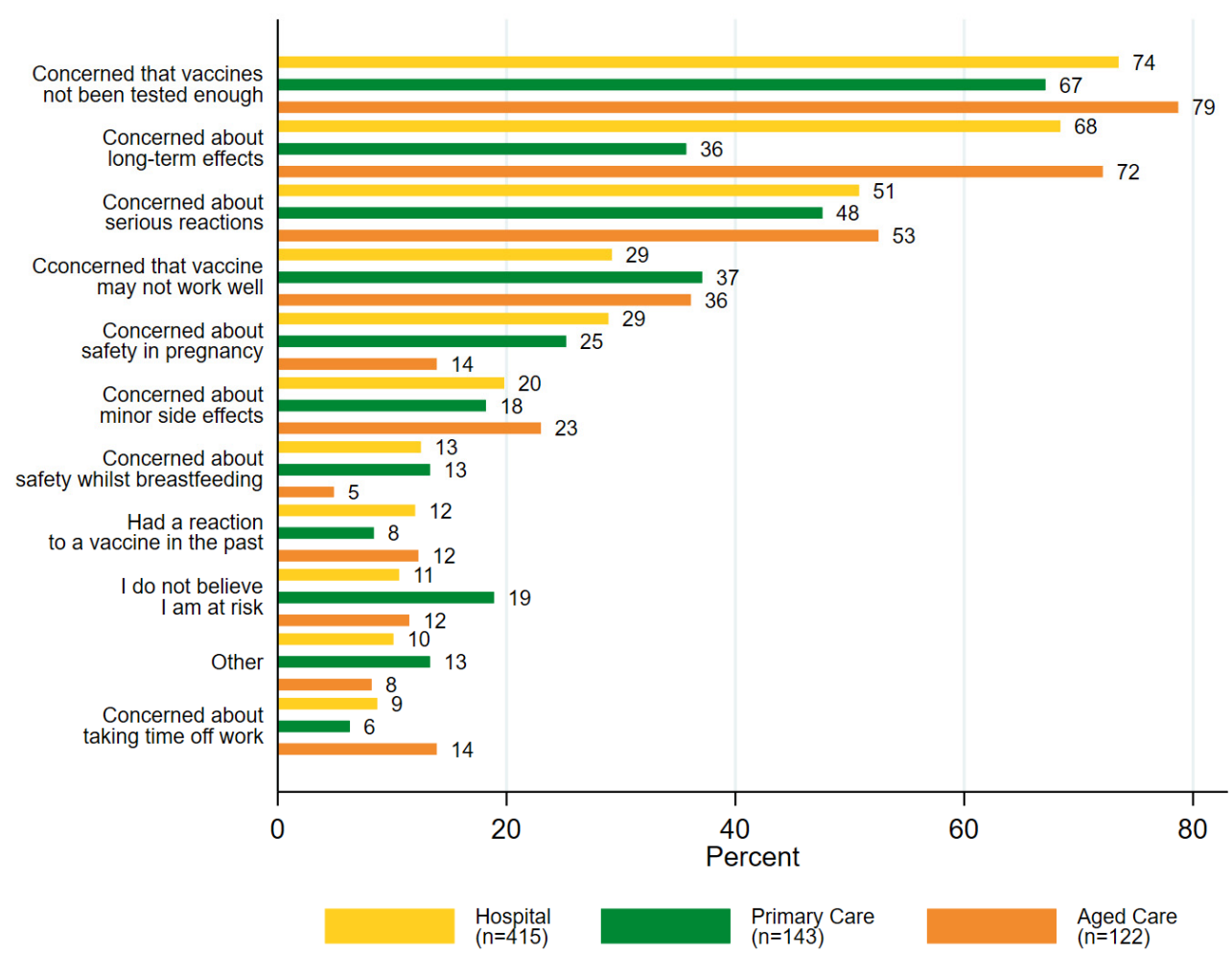

Figure 3. Concerns of HCWs (\% selected) who were unsure or did not intend to accept a COVID-19 vaccine $(n=680)$, by setting. 


\subsubsection{Perceived Risks of COVID-19}

Forty two percent of HCWs $(42 \%, 1287 / 3069)$ were very or moderately concerned about getting COVID-19 themselves, with negligible difference across settings. Approximately half of all HCWs across settings were not concerned about passing COVID-19 to their patients, with those working in aged care $(59 \%, 215 / 363)$ more concerned than those in primary care $(51 \%, 456 / 895)$ or hospitals $(49 \%, 891 / 1808)$ (Table S3). However, in the hospital setting, HCWs who were concerned about passing COVID-19 to their patients were more likely to accept a vaccine, compared to those who were not concerned (adjusted risk difference $9 \%, 95 \%$ CI 5 to $12 \%$ ). There was no evidence of associations between perceived risks of COVID-19 and the intention to receive a vaccination in other settings (Table 3).

\subsubsection{Beliefs about COVID-19 Vaccines}

Across all settings, trust in the vaccines and the belief that the vaccines were important, safe, would protect others and would not cause a serious reaction were strongly associated with the intention to vaccinate (Table 3). HCWs in primary care settings had the highest rate of agreement across these COVID-19 vaccine beliefs, while those working in aged care had the lowest (Table S3).

\subsection{Practical Issues}

\subsubsection{Information about COVID-19 Vaccines}

Only 25\% (782/3074) of participants felt they had enough information about all five of the following COVID-19 vaccine topics: how the COVID-19 vaccines work, vaccine effectiveness, vaccine safety, vaccine side effects and vaccine dose and interval recommendations (Table S3). Those working in aged care settings felt the least informed about each topic. Compared to HCWs across settings who did not feel informed about at least one topic, HCWs who felt sufficiently informed about all five topics had higher vaccine intentions; after adjusting for demographics, vaccine intentions were $20 \%$ higher for hospital HCWs ( $95 \%$ CI 17 to $22 \%$ ), 13\% higher for primary care HCWs (95\% CI 9 to $17 \%$ ) and $32 \%$ higher in aged care (95\% CI 25 to $39 \%$ ) (Table 3).

\subsubsection{Perceived Convenience of COVID-19 Vaccination}

Most participants $(82 \%, 2503 / 3056)$ thought it would be moderately or very convenient to get a COVID-19 vaccine. Fewer of those working in aged care settings thought it would be convenient $(76 \%, 276 / 362)$ compared to those working in primary care $(80 \%, 708 / 894)$ or hospital settings $(84 \%, 1519 / 1800)$. Across all settings, the primary concern among those who thought it would not be very convenient to get the vaccine was organising an appointment at a suitable time $(45 \%, 758 / 1703)$. For those in aged care settings, the next most common concern was travelling to the vaccine location $(28 \%, 63 / 229)$. However, the second most common concern for those in the hospital setting was knowing which vaccine priority group they were in $(33 \%, 297 / 903)$, and for primary care HCWs it was long wait times $(41 \%, 231 / 571)$. Intention to vaccinate was significantly higher among HCWs who thought it would be convenient to receive a COVID-19 vaccine. The greatest difference in the intention was seen in the aged care setting, where perceived convenience was associated with a $44 \%$ (95\% CI 32 to $57 \%$ ) increase in the intention to vaccinate (Table 3). Participants work setting was the preferred location to get a COVID-19 vaccine; $86 \%(1550 / 1881)$ of hospital-based workers preferred vaccination in hospital, $64 \%(576 / 898)$ of primary care participants at a general practice, and 58\% (211/365) of aged care participants preferred residential aged/disability care settings. 
Table 3. Thoughts and feelings and practical issues related to COVID-19 vaccination and associations with intentions, by HCW setting.

\begin{tabular}{|c|c|c|c|c|c|c|}
\hline \multirow{3}{*}{$\begin{array}{l}\text { Thoughts and Feelings } \\
\text { and Practical Issues }\end{array}$} & \multicolumn{3}{|c|}{ Would Get the COVID-19 Vaccine?Yes, \% $(n / \mathrm{N})$} & \multicolumn{3}{|c|}{ Adjusted Risk Difference ${ }^{\wedge} *(95 \%$ CI, $p$-Value $)$} \\
\hline & Hospital & Primary Care & Aged Care & Hospital & Primary Care & Aged Care \\
\hline & $\mathbf{N}=1811$ & $\mathrm{~N}=898$ & $\mathbf{N}=365$ & & & \\
\hline \multicolumn{7}{|c|}{ Perceived risks of COVID-19 } \\
\hline \multicolumn{7}{|c|}{ Concerned about getting COVID-19^ } \\
\hline Not at all/A little & $75.1(789 / 1050)$ & $82.4(430 / 522)$ & $69.5(146 / 210)$ & & & \\
\hline Very/Moderately & $79.9(605 / 757)$ & $86.7(325 / 375)$ & $62.6(97 / 155)$ & $\begin{array}{c}2.9 \\
(-0.9 \text { to } 6.6 ; 0.139)\end{array}$ & $\begin{array}{c}4.2 \\
(0.1 \text { to } 8.4 ; 0.050)\end{array}$ & $\begin{array}{c}4.2 \\
(-14.8 \text { to } 6.3 ; 0.430)\end{array}$ \\
\hline \multicolumn{7}{|c|}{ Concerned about your patients or residents getting COVID-19 from you ${ }^{\wedge}$} \\
\hline Not at all/A little & $71.5(656 / 917)$ & $81.5(358 / 439)$ & $60.1(89 / 148)$ & & & \\
\hline Very/Moderately & $82.9(739 / 891)$ & $86.4(394 / 456)$ & $71.6(154 / 215)$ & $\begin{array}{c}8.6 \\
(4.9 \text { to } 12.3 ;<0.001)\end{array}$ & $\begin{array}{c}2.4 \\
(-1.9 \text { to } 6.7 ; 0.260)\end{array}$ & $\begin{array}{c}-1.4 \\
(-11.6 \text { to } 8.8 ; 0.790)\end{array}$ \\
\hline \multicolumn{7}{|c|}{ Beliefs about the COVID-19 vaccine } \\
\hline \multicolumn{7}{|c|}{ Trust the new COVID-19 vaccines $^{\text {m }}$} \\
\hline Very/moderately & $93.6(1290 / 1378)$ & $94.6(717 / 758)$ & $93.7(222 / 237)$ & $66.3(61.3$ to $71.2 ;<0.001)$ & $\begin{array}{c}63.2 \\
(54.0 \text { to } 72.5 ;<0.001)\end{array}$ & $\begin{array}{c}50.7 \\
(50.7 \text { to } 50.7 ;<0.001) \\
\end{array}$ \\
\hline \multicolumn{7}{|c|}{ Think getting a COVID-19 vaccine will be important for your health ${ }^{\wedge}$} \\
\hline Not at all/A little & $25.4(88 / 346)$ & $25.7(35 / 136)$ & $16.1(18 / 112)$ & & & \\
\hline Very/moderately & $89.4(1296 / 1450)$ & $94.6(718 / 759)$ & $89.2(223 / 250)$ & $\begin{array}{c}60.5 \\
(54.8 \text { to } 66.2 ;<0.001)\end{array}$ & $\begin{array}{c}59.5 \\
(49.9 \text { to } 69.0 ;<0.001)\end{array}$ & $\begin{array}{c}36.7 \\
(-92.4 \text { to } 165.9 ; 0.580)\end{array}$ \\
\hline \multicolumn{7}{|c|}{ Think getting a COVID-19 vaccine will protect other people in your community from COVID-19 ${ }^{\wedge}$} \\
\hline Not at all/A little & $21.6(63 / 292)$ & $28.2(33 / 117)$ & $12.0(12 / 100)$ & & & \\
\hline Very/moderately & $87.8(1321 / 1504)$ & $92.5(712 / 770)$ & $87.4(229 / 262)$ & $\begin{array}{c}61.5 \\
(55.4 \text { to } 67.7 ;<0.001)\end{array}$ & $\begin{array}{c}41.1 \\
(31.2 \text { to } 51.0 ;<0.001)\end{array}$ & $\begin{array}{c}58.8 \\
(58.7 \text { to } 58.8 ;<0.001)\end{array}$ \\
\hline
\end{tabular}


Table 3. Cont.

\begin{tabular}{|c|c|c|c|c|c|c|}
\hline \multirow{3}{*}{$\begin{array}{l}\text { Thoughts and Feelings } \\
\text { and Practical Issues }\end{array}$} & \multicolumn{3}{|c|}{ Would Get the COVID-19 Vaccine?Yes, \% $(n / \mathrm{N})$} & \multicolumn{3}{|c|}{ Adjusted Risk Difference ${ }^{\wedge}, *(95 \%$ CI, $p$-Value $)$} \\
\hline & Hospital & Primary Care & Aged Care & Hospital & Primary Care & Aged Care \\
\hline & $\mathbf{N}=1811$ & $\mathrm{~N}=898$ & $\mathbf{N}=365$ & & & \\
\hline \multicolumn{7}{|c|}{ Think a COVID-19 vaccine will be safe for you ${ }^{\text {^ }}$} \\
\hline Not at all/A little & $23.9(104 / 436)$ & $27.8(40 / 144)$ & $12.9(15 / 116)$ & & & \\
\hline Very/moderately & $94.0(1279 / 1361)$ & $95.0(709 / 746)$ & $91.9(226 / 246)$ & $\begin{array}{c}67.0 \\
(62.0 \text { to } 71.9 ;<0.001)\end{array}$ & $\begin{array}{c}59.6 \\
(50.3 \text { to } 68.9 ;<0.001)\end{array}$ & $\begin{array}{c}52.1 \\
(47.4 \text { to } 56.8 ;<0.001)\end{array}$ \\
\hline \multicolumn{7}{|c|}{ Concerned that a COVID-19 vaccine could cause you to have a serious reaction ${ }^{\text {^ }}$} \\
\hline Not at all/A little & $51.5(333 / 647)$ & $62.4(156 / 250)$ & $47.6(91 / 191)$ & & & \\
\hline Very/moderately & $91.4(1055 / 1154)$ & $92.5(594 / 642)$ & $87.8(151 / 172)$ & $\begin{array}{c}37.6 \\
(-42.1 \text { to }-33.1 ;<0.001)\end{array}$ & $\begin{array}{c}22.1 \\
\text { (15.4 to } 28.7 ;<0.001)\end{array}$ & $\begin{array}{c}37.6 \\
\text { (28.1 to } 47.1 ;<0.001)\end{array}$ \\
\hline \multicolumn{7}{|c|}{ Sufficient information about COVID-19 vaccines } \\
\hline $\begin{array}{c}\text { Not informed about at } \\
\text { least one of the five } \\
\text { issues }\end{array}$ & $71.2(945 / 1328)$ & $79.5(495 / 623)$ & $58.5(155 / 265)$ & & & \\
\hline \multicolumn{7}{|c|}{ Perceived convenience of getting a COVID-19 vaccine } \\
\hline Not at all/A little & $48.8(137 / 281)$ & $71.5(133 / 186)$ & $29.1(25 / 86)$ & & & \\
\hline Very/moderately & $82.3(1250 / 1519)$ & $87.4(619 / 708)$ & $79.0(218 / 276)$ & $\begin{array}{c}29.6 \\
(22.7 \text { to } 36.5 ;<0.001)\end{array}$ & $\begin{array}{c}11.1 \\
(4.4 \text { to } 17.9 ;<0.001)\end{array}$ & $\begin{array}{c}44.4 \\
(32.2 \text { to } 56.6 ;<0.001)\end{array}$ \\
\hline
\end{tabular}




\subsubsection{Employer Requirements}

Forty two percent of those working in aged care settings (42\%, 153/362) felt that COVID-19 vaccination should be mandated for all healthcare workers, compared to $54 \%$ (484/893) of HCWs in primary care settings and 50\% (907/1806) of HCWs in hospitals. More than half of all HCWs $(57 \%, 1754 / 3058)$ said they would be more likely to get vaccinated if required by their employer. Of those who did not intend to get the vaccine, $23 \%$ (159/676) indicated that they would be more likely to get vaccinated if their employer required it. This potentially influenceable group included more women, more working in aged care settings and more with no comorbidities (Table S4), compared to participants who either planned to get vaccinated or did not plan to get vaccinated, and would not be influenced by an employer requirement.

\subsubsection{Communication Preferences}

HCWs from all settings preferred to receive information from government websites or sources $(62 \%, 1899 / 3074)$ and through discussions with their primary healthcare provider $(29 \%, 882 / 3074)$ (Table S3). The top three most trusted spokespeople to provide information about COVID-19 vaccines for HCWs across all settings were medical professionals (73\%, $2249 / 3074)$, scientists or researchers $(60 \%, 1839 / 3074)$, and participants' personal healthcare provider $(23 \%, 705 / 3074)$. However, compared to hospital and primary care HCWs, those working in aged care settings reported comparatively lower levels of trust for medical professionals $(61 \%, 224 / 365)$ and scientists $(48 \%, 174 / 365)$.

Hospital and aged care HCWs preferred to hear about the time and location of their personal COVID-19 vaccination appointment from their employer. However, people working in primary care settings preferred their primary healthcare provider to communicate this information. Primary care providers also rated "my union or professional body" highly as a preferred information source, unlike hospital or aged care HCWs. Government representatives were not widely preferred as information sources about appointment time and location of vaccination.

Across all settings, printed materials for patients were most frequently selected to support discussions with patients (hospital 76\%, 1377/1811; primary care 78\%, 699/898; aged care $67 \%, 243 / 365)$. Approximately 61\% (1878/3074) of HCWs across all settings wanted training modules providing strategies for difficult discussions. In aged care settings, online information for patients was less valued $(32 \%, 118 / 365)$ than it was in hospital $(55 \%$, $988 / 1811)$ or primary care settings $(56 \%, 498 / 989)$.

\section{Discussion}

This study was among the first to assess the vaccine intention and the factors driving uptake for front-line healthcare workers in Victoria, Australia at the start of the COVID-19 vaccine rollout. Our findings indicate that most ( $80 \%$ overall) HCWs were planning to accept a COVID-19 vaccine, but highlighted some key differences in concerns, beliefs, perceptions and communication preferences between HCWs in hospitals, primary care and aged or disability care settings.

While the majority of fatalities during Melbourne's second wave in 2020 were in aged care settings [27], a surprisingly high proportion of HCWs in aged care did not report high concerns about passing COVID-19 to others. People working in aged or disability care settings had a lower intention to be vaccinated and were less likely to believe the vaccines were safe, important and effective than those working in hospitals or primary care settings. Other countries have also identified low rates of vaccine acceptance or uptake for nonhospital settings and patient care assistants [28]. A United States study in early 2021 found that approximately one-third of those working in nursing homes or assisted care facilities were not intending to receive (24\%) or yet to decide (11\%) about the COVID-19 vaccine [28]. Our participants in the aged or disability care setting also felt the least informed about key vaccine topics. Some staff in aged care settings may not have a background in health or high levels of health literacy, and so we cannot assume that they have sufficient understanding 
or confidence in their knowledge about vaccination [29]. Another reason for this gap may be due to the lack of appropriately tailored and translated communication materials, given that more than a quarter $(27 \%)$ of our participants from aged or disability care settings spoke a language other than English at home. Inappropriate or insufficient information in different languages and for different levels of health [30] and e-Health literacy [31] has been an issue highlighted repeatedly throughout the pandemic but particularly during the vaccine rollout [32,33]. Aged and disability care workers are also more likely to be employed part time, compared with hospital or primary care HCWs, and there are fewer professional unions or organisations with wide membership across this workforce. These factors likely impact dissemination of key public health information to these workers. A key lesson for governments to take away from the COVID-19 pandemic should be the importance of establishing reliable communication channels with those working in the aged and disability care setting. This includes utilising trusted spokespeople as well as being more aware of the challenges posed by different levels of health literacy.

Half of HCWs (50\%) were supportive of a vaccine requirement for all HCWs, and nearly a quarter of those who did not plan to get the vaccine said they would if their employer required it. Vaccine mandates are a potentially powerful tool to increase vaccine uptake, but key criteria should be met before implementation [34]. In particular, safe and effective vaccines must be easily accessible, culturally appropriate information and education should be provided, and less restrictive measures should be tried first [34]. While many participants supported the idea of vaccine mandates at the time of our study, other studies overseas $[8,35,36]$ have identified resistance to these policies among healthcare workers. Results from the USA reported that only $35 \%$ of healthcare workers thought the vaccine should be mandated by their employers or the government [8]. Australia has not seen widespread resignations $[37,38]$ in the face of recent mandates for aged care workers [39] and healthcare workers in Victoria [15] and New South Wales [16]. However, rapidly implemented vaccine mandates could damage trust [40] in government policy, which may have implications for acceptance of COVID-19 booster doses, or even uptake of other vaccines.

Our findings highlight the importance of ensuring that vaccination is convenient and accessible, particularly for prioritised workforces such as HCWs. Across all settings, participants who thought it would be convenient were significantly more likely to accept a COVID-19 vaccine. In the aged care rollout, issues arose when workers were told they could not access the vaccine on site [41,42]. Low uptake due to access barriers is often misconstrued as vaccine hesitancy. In future vaccine rollouts, it is key to assess both access and acceptance [43] and proactively develop strategies to address both.

Healthcare workers across all settings lacked information about key COVID-19 vaccine topics even as the vaccine rollout was underway. To support their discussions with patients, they wanted printed materials in preference to online information. However, the information provided needs to be easy to read, with recent reports indicating government information about vaccines is not only difficult to read [32,33], but that Australian materials are more difficult than those in the USA and UK [33]. Even HCWs in roles or settings that were not directly involved in delivering COVID-19 vaccines were willing to discuss and recommend vaccines to their patients, and they were keen for communication training to support difficult vaccine discussions. This training should reflect evidence-based recommendations to build confidence in the vaccines and communicate about vaccine risks and benefits $[44,45]$.

\section{Strengths, Limitations and Future Research}

Our study has a number of strengths, including being the first Australian multidisciplinary, large-scale survey targeting healthcare workers prioritised to receive the vaccines. Our comparison of findings across three key healthcare settings is a particular strength and relatively uncommon in the global literature. This disaggregation is critical to inform targeted strategies to improve vaccine acceptance and uptake, and it will be relevant 
for booster dose campaigns as well as future pandemic vaccination strategies. HCWs in a range of roles and from both metropolitan and regional areas were included. During our survey period, there were no age limitations for use of specific brands of vaccine, and no major safety signals had yet emerged. Subsequently, the Australian Technical Advisory Group on Immunisation (ATAGI) recommended Pfizer as the preferred vaccine for all adults under 50 years from April 2021 [46]. Despite some media debate at the time around the effectiveness of different vaccine brands, brand preferences were not associated with intentions in the current study. However, this issue would go on to become a factor affecting uptake later in the rollout. Further limitations must also be considered. Our sample was not nationally representative, nor were our data weighted for analysis, due to the difficulties in accessing robust HCW numbers stratified by age, sex and profession. The majority of our participants were nurses, with small numbers for personal support workers and pharmacists, despite intensive efforts to recruit from these groups. This study was conducted during the first quarter of 2021 under time pressure to inform the pandemic response and at the beginning of the vaccination program rollout. We did not examine the effectiveness of communication materials in addressing HCWs' concerns about COVID-19 vaccines, which should be the focus of future research. Consideration of utilising health professionals or pharmacists to be COVID-19 vaccine champions may facilitate uptake in lower intention or uptake groups across HCW settings.

\section{Conclusions}

Although the majority of HCWs expressed a high intention to vaccinate early in the COVID-19 vaccine rollout in Victoria, this study identified clear areas for targeted interventions across the different healthcare settings to support equitable uptake of COVID19 and other vaccines for HCWs. Strategies such as easily accessible vaccination stations in HCWs' workplace settings, easy-to-read and culturally appropriate information to address negative beliefs, support for healthcare workers themselves and for discussions with hesitant patients would be helpful. While generally supported, mandatory vaccination policies should be implemented with careful planning and consultation to avoid unintended consequences. By meeting vaccination uptake targets, we can be confident that our HCWs are safe and available to deliver patient care.

Supplementary Materials: The following are available online at https:/ /www.mdpi.com/article/10 .3390/vaccines10010003/s1: Table S1: Survey items and sources; Table S2: Factors influencing the decision, by total sample; Table S3: All descriptive analyses; Table S4: Demographic characteristics by intention to vaccinate and/or required to vaccinate by employer.

Author Contributions: Conceptualization, J.K., J.L., H.S., R.B., L.S., J.-A.M.-N., J.S.B., J.M. and M.D.; formal analysis, J.K., K.L.B., M.H. and M.D.; funding acquisition, J.K. and M.D.; methodology, J.K., M.H., J.L., H.S., R.B., L.S., J.-A.M.-N., J.S.B., J.M., C.J., D.S.O. and M.D.; project administration, J.K. and D.S.O.; supervision, M.D.; writing—original draft, J.K., K.L.B. and M.H.; writing-review and editing, J.K., K.L.B., M.H., J.L., H.S., R.B., L.S., J.-A.M.-N., J.S.B., J.M., C.J., D.S.O., J.O., J.T. and M.D. All authors have read and agreed to the published version of the manuscript.

Funding: This research was funded by the Victorian Government (C9824). The funders provided input into survey design but had no role in collection, analysis or interpretation of the data, in the writing of the manuscript, or in the decision to publish the results.

Institutional Review Board Statement: The study was conducted according to the guidelines of the Declaration of Helsinki and approved by the Royal Children's Hospital Human Research Ethics Committee (HREC/72845/RCHM-2021).

Informed Consent Statement: Informed consent was obtained from all participants through the provision of the Participant Consent and Information Form and subsequent completion of the survey (implied consent)

Data Availability Statement: Restrictions apply to the availability of these data. Data are available from the authors upon request and with the permission of the Victorian Department of Health. 
Acknowledgments: We would like to acknowledge the project advisory group members: Stefanie Johnston (Pharmaceutical Society of Australia), Belinda Hibble (Australasian College for Emergency Medicine), Ken Griffin (Australian Primary Health Care Nurses Association), Amy Miller and Melanie Chisholm (Victorian Department of Health), Stephen Peterson (consumer representative), Talei Richards (Victorian Multicultural Commission), Shanthi Gardiner (Australian Primary Health Care Nurses Association) and Deepak Gaur (Australian Medical Association). We would also like to thank the specialist organisations that supported our recruitment efforts, and the participants who gave their time and stories to our research team; networks and organisations involved in advertising our study are as follows: Australasian College of Emergency Medicine, College of Intensive Care Medicine, Postgraduate Medical Council of Victoria, Australian Medical Association Victoria, Australian Nursing and Midwifery Federation, Ambulance Victoria and health services professional unions and networks (e.g., the Victorian Doctors Health and Wellbeing Network), Victorian Primary Care Practice-based Research Network, Department of General Practice, University of Melbourne; Victorian Faculty of the Royal Australian College of General Practitioners; Australian Primary Health Care Nurses Association; Australasian Association for Academic Primary Care; relevant Facebook groups (e.g., GPs Down Under, Doc to Doc, Melbourne Medical Mums and Mums to Be); Primary Health Networks; Pharmaceutical Society of Australia, Safer Care Victoria; Aged \& Community Services Australia; Leading Age Services Australia; relevant Facebook groups.

Conflicts of Interest: J.K., K.B., J.T., D.S.O., C.J., J.O. and M.D.'s institution MCRI receives funding from the Commonwealth and Victorian Department of Health for COVID-19 vaccine social research. J.T. is an investigator on a project grant sponsored by industry. Her institution has received funding from industry (GlaxoSmithKline) for investigator-led research. She does not receive any personal payments from industry. J.S.B. has received grant funding or consulting funds from the National Health and Medical Research Council (NHMRC), Victorian Government Department of Health, Dementia Australia Research Foundation, Yulgilbar Foundation, Aged Care Quality and Safety Commission, Dementia Centre for Research Collaboration, Pharmaceutical Society of Australia, GlaxoSmithKline Supported Studies Programme, Amgen, and several aged care provider organisations unrelated to this work. All grants and consulting funds were paid to the employing institution. H.S. is a listed investigator on studies receiving funding from the NHMRC. She is also receiving funding for investigator-driven research from state government. She has previously received funding from drug companies for investigator-driven research and consulting fees to present at conferences/workshops and develop resources (Seqirus, GlaxoSmithKline and Sanofi Pasteur). M.D. receives funding from the NHMRC. She also sits on the Australian Technical Advisory Group on Immunisation advising the Commonwealth on COVID-19 vaccination communications and confidence and is a Specialist Advisor to the Vaccine Safety Investigation Group of the Therapeutic Goods Administration. J.M.N. receives funding from the NHMRC and MRFF. J.L. receives funds from WHO, UNICEF, CDC and NHMRC. She is a member of the Expert Advisory Group for the Victorian Department of Health and Human Services COVID-19 vaccine rollout.

\section{References}

1. Dooling, K.; Marin, M.; Wallace, M.; McClung, N.; Chamberland, M.; Lee, G.M.; Talbot, H.K.; Romero, J.R.; Bell, B.P.; Oliver, S.E. The Advisory Committee on Immunization Practices' Updated Interim Recommendation for Allocation of COVID-19 Vaccine-United States, December 2020. Morb. Mortal. Wkly. Rep. (MMWR) 2020, 69, 1657-1660. [CrossRef] [PubMed]

2. Public Health England. COVID-19 Vaccination First Phase Priority Groups. Available online: https://www.gov.uk/government/ publications / covid-19-vaccination-care-home-and-healthcare-settings-posters / covid-19-vaccination-first-phase-prioritygroups (accessed on 2 August 2021).

3. Australian Government. Australia's COVID-19 Vaccine National Roll-Out Strategy Announced. Available online: https: / / www.health.gov.au/news/australias-covid-19-vaccine-national-roll-out-strategy-announced (accessed on 28 June 2021).

4. New Zealand Government. COVID-19 Vaccine Rollout Groups. Available online: https://covid19.govt.nz/covid-19-vaccines/ our-covid-19-vaccination-plan/covid-19-vaccine-rollout-groups/\#group-3-\%E2\%80\%94-getting-underway (accessed on 28 June 2021).

5. Sallam, M. COVID-19 Vaccine Hesitancy Worldwide: A Concise Systematic Review of Vaccine Acceptance Rates. Vaccines 2021, 9 , 160. [CrossRef] [PubMed]

6. Salomoni, M.G.; Di Valerio, Z.; Gabrielli, E.; Montalti, M.; Tedesco, D.; Guaraldi, F.; Gori, D. Hesitant or Not Hesitant? A Systematic Review on Global COVID-19 Vaccine Acceptance in Different Populations. Vaccines 2021, 9, 873. [CrossRef]

7. Li, M.; Luo, Y.; Watson, R.; Zheng, Y.; Ren, J.; Tang, J.; Chen, Y. Healthcare workers' (HCWs) attitudes and related factors towards COVID-19 vaccination: A rapid systematic review. Postgrad. Med. J. 2021. [CrossRef] [PubMed] 
8. Shekhar, R.; Sheikh, A.B.; Upadhyay, S.; Singh, M.; Kottewar, S.; Mir, H.; Barrett, E.; Pal, S. COVID-19 Vaccine Acceptance among Health Care Workers in the United States. Vaccines 2021, 9, 119. [CrossRef]

9. Hajure, M.; Tariku, M.; Bekele, F.; Abdu, Z.; Dule, A.; Mohammedhussein, M.; Tsegaye, T. Attitude Towards COVID-19 Vaccination among Healthcare Workers: A Systematic Review. Infect. Drug Resist. 2021, 14, 3883-3897. [CrossRef]

10. Hall, V.J.; Foulkes, S.; Saei, A.; Andrews, N.; Oguti, B.; Charlett, A.; Wellington, E.; Stowe, J.; Gillson, N.; Atti, A.; et al. COVID-19 vaccine coverage in health-care workers in England and effectiveness of BNT162b2 mRNA vaccine against infection (SIREN): A prospective, multicentre, cohort study. Lancet 2021, 397, 1725-1735. [CrossRef]

11. Tulloch, J.S.P.; Lawrenson, K.; Gordon, A.L.; Ghebrehewet, S.; Ashton, M.; Peddie, S.; Parvulescu, P. COVID-19 vaccine hesitancy in care home staff: A survey of Liverpool care homes. medRxiv 2021. [CrossRef]

12. Victorian Department of Health. Victorian Healthcare Worker (Clinical and Non-Clinical) COVID-19 Data. Available online: https:/ / www.coronavirus.vic.gov.au/healthcare-worker-covid-19-data (accessed on 10 November 2021).

13. Australian Government. COVID-19 Vaccine Roll-Out. Available online: https://www.health.gov.au/sites/default/files/ documents/2021/11/covid-19-vaccine-rollout-update-10-november-2021.pdf (accessed on 10 November 2021).

14. Department of Health, Australian Government. COVID-19 Vaccination to Become Mandatory for Residential Aged Care Workers. Available online: https:/ / www.health.gov.au/news/announcements/covid-19-vaccination-to-become-mandatoryfor-residential-aged-care-workers (accessed on 29 July 2021).

15. Victorian Department of Health. COVID-19 Mandatory Vaccination Directions (No 1). Available online: https://www.dhhs. vic.gov.au/sites/default/files/documents/202109/covid-19-mandatory-vaccination-directions.pdf (accessed on 10 November 2021).

16. New South Wales. Public Health (COVID-19 Vaccination of Health Care Workers) Order 2021. Available online: https: / / legislation.nsw.gov.au/file/Public\%20Health\%20(COVID-19\%20Vaccination\%20of\%20Health\%20Care\%20Workers) \%20Order\%202021_210826_9.54am.pdf (accessed on 10 November 2021).

17. Kaufman, J.; Bagot, K.L.; Tuckerman, J.; Biezen, R.; Oliver, J.; Jos, C.; Suryawijaya Ong, D.; Manski-Nankervis, J.-A.; Seale, H.; Sanci, L.; et al. Qualitative exploration of intentions, concerns and information needs of vaccine hesitant adults initially prioritised to receive COVID-19 vaccines in Australia. Aust. N. Z. J. Public Health 2021. [CrossRef]

18. Business Victoria, Victorian Government. Victoria to Return to COVIDSafe Summer with Some Changes to Restrictions. 17 February 2021. Available online: https:/ / www.premier.vic.gov.au/statement-premier-86 (accessed on 10 November 2021).

19. Victorian Government; Health and Human Services. Coronavirus Update for Victoria-26 March 2021. 2021. Available online: https:/ / www.dhhs.vic.gov.au/coronavirus-update-victoria-26-march-2021 (accessed on 10 November 2021).

20. Hitch, G.; Swanston, T. Health officials back AstraZeneca vaccine rollout amid calls for more Pfizer doses. ABC News, 13 January 2021.

21. Smyth, J. Australian scientists cast doubt on Oxford/AstraZeneca vaccine. Financial Times, 13 January 2021.

22. World Health Organization. WHO statement on AstraZeneca COVID-19 vaccine safety signals. WHO News, 17 March 2021.

23. Shapiro, G.K.; Kaufman, J.; Brewer, N.T.; Wiley, K.; Menning, L.; Leask, J.; Abad, N.; Betsch, C.; Bura, V.; Correa, G.; et al. A critical review of measures of childhood vaccine confidence. Curr. Opin. Immunol. 2021, 71, 34-45. [CrossRef]

24. Harris, P.A.; Taylor, R.; Minor, B.L.; Elliott, V.; Fernandez, M.; O’Neal, L.; McLeod, L.; Delacqua, G.; Delacqua, F.; Kirby, J.; et al. The REDCap consortium: Building an international community of software partners. J. Biomed. Inform. 2019, 95, 103208. [CrossRef] [PubMed]

25. World Health Organization. Data for Action: Achieving High Uptake of COVID-19 Vaccines; BeSD COVID-19 Working Group, Ed.; WHO: Geneva, Switzerland, 2021.

26. StataCorp. Stata Statistical Software: Release 15; StataCorp LP: College Station, TX, USA, 2019.

27. Australian Government Department of Health. COVID-19 Outbreaks in Australian Residential Aged Care Facilities: National Snapshot. Available online: https:/ /www.health.gov.au/news/health-alerts/novel-coronavirus-2019-ncov-health-alert/ coronavirus-covid-19-case-numbers-and-statistics\#cases-in-aged-care-services (accessed on 10 November 2021).

28. Kirzinger, A.; Kearney, A.; Hamel, L.; Brodie, M. KFF/The Washington Post Frontline Health Care Workers Survey. Available online: https: / / www.kff.org/coronavirus-covid-19/poll-finding/kff-washington-post-health-care-workers / (accessed on 28 July 2021).

29. Dodd, R.H.; Pickles, K.; Cvejic, E.; Cornell, S.; Isautier, J.M.; Copp, T.; Nickel, B.; Bonner, C.; Batcup, C.; Muscat, D.M.; et al. Perceived public health threat a key factor for willingness to get the COVID-19 vaccine in Australia. Vaccine 2021, in press. [CrossRef]

30. Bin Naeem, S.; Kamel Boulos, M.N. COVID-19 Misinformation Online and Health Literacy: A Brief Overview. Int. J. Environ. Res. Public Health 2021, 18, 8091. [CrossRef]

31. An, L.; Bacon, E.; Hawley, S.; Yang, P.; Russell, D.; Huffman, S.; Resnicow, K. Relationship between Coronavirus-Related eHealth Literacy and COVID-19 Knowledge, Attitudes, and Practices among US Adults: Web-Based Survey Study. J. Med. Internet Res. 2021, 23, e25042. [CrossRef]

32. Mac, O.A.; Muscat, D.; Ayre, J.; Patel, P.; McCaffery, K.J. Coronavirus (COVID-19) vaccination information must pay attention to health literacy: Analysis of readability of official COVID-19 public health information. Med. J. Aust. 2021. pre-print.

33. Ferguson, C.; Merga, M.; Winn, S. Communications in the time of a pandemic: The readability of documents for public consumption. Aust. N. Z. J. Public Health 2021, 45, 116-121. [CrossRef] 
34. Leask, J.; Seale, H.; Williams, J.H.; Kaufman, J.; Wiley, K.; Mahimbo, A.; Clark, K.K.; Danchin, M.; Attwell, K. Policy considerations for mandatory COVID-19 vaccination from the Collaboration on Social Science in Immunisation. Med. J. Aust. 2021, 215, 499-503. [CrossRef] [PubMed]

35. Riccò, M.; Ferraro, P.; Peruzzi, S.; Balzarini, F.; Ranzieri, S. Mandate or Not Mandate: Knowledge, Attitudes, and Practices of Italian Occupational Physicians towards SARS-CoV-2 Immunization at the Beginning of Vaccination Campaign. Vaccines 2021, 9 , 889. [CrossRef]

36. Shaw, J.; Stewart, T.; Anderson, K.B.; Hanley, S.; Thomas, S.J.; Salmon, D.A.; Morley, C. Assessment of U.S. health care personnel (HCP) attitudes towards COVID-19 vaccination in a large university health care system. Clin. Infect. Dis. Off. Publ. Infect. Dis. Soc. Am. 2021, 73, 1776-1783. [CrossRef] [PubMed]

37. Davey, M. Royal Melbourne hospital down 51 staff who won't comply with Covid vaccine mandate. The Guardian, 2 November 2021.

38. McGowan, M. Fewer than than $0.1 \%$ of NSW health staff have quit due to Covid vaccination mandates. The Guardian, 8 October 2021.

39. Australian Government Department of Health. Mandatory Vaccination of Residential Aged Care Workers. Available online: https:/ / www.health.gov.au/resources/publications/covid-19-vaccination-mandatory-vaccination-of-residential-agedcare-workers (accessed on 10 November 2021).

40. Helps, C.; Leask, J.; Barclay, L. “It just forces hardship": Impacts of government financial penalties on non-vaccinating parents. J. Public Health Policy 2018, 39, 156-169. [CrossRef]

41. Knaus, C. Australian aged care workers relying on spare Covid vaccines and confusing advice, survey finds. The Guardian, 21 April 2021.

42. Knaus, C. 'Another level of confusion': Private contractors at odds over whether they were meant to vaccinate aged care staff. The Guardian, 5 June 2021.

43. Kaufman, J.; Tuckerman, J.; Bonner, C.; Durrheim, D.N.; Costa, D.; Trevena, L.; Thomas, S.; Danchin, M. Parent-level barriers to uptake of childhood vaccination: A global overview of systematic reviews. BMJ Glob. Health 2021, 6, e006860. [CrossRef] [PubMed]

44. Danchin, M.; Biezen, R.; Manski-Nankervis, J.A.; Kaufman, J.; Leask, J. Preparing the public for COVID-19 vaccines: How can general practitioners build vaccine confidence and optimise uptake for themselves and their patients? Aust. J. Gen. Pract. 2020, 49, 625-629. [CrossRef] [PubMed]

45. Leask, J.; Carlson, S.J.; Attwell, K.; Clark, K.K.; Kaufman, J.; Hughes, C.; Frawley, J.; Cashman, P.; Seale, H.; Wiley, K.; et al. Communicating with patients and the public about COVID-19 vaccine safety: Recommendations from the Collaboration on Social Science in Immunisation. Med. J. Aust. 2021, 215, 9-12. [CrossRef] [PubMed]

46. Therapeutic Goods Administration, Department of Health, Australian Government. The Australian Technical Advisory Group on Immunisation (ATAGI) Advice on the AstraZeneca COVID-19 Vaccine in Response to New Vaccine Safety Concerns. Available online: https:/ / www.tga.gov.au/media-release/astrazeneca-chadox1-s-covid-19-vaccine (accessed on 28 June 2021). 